\title{
Research on the Optimization of Express Service Network Based on Carbon Emission
}

\author{
Baohua Shen ${ }^{1, a^{*}}$, Juan Jiang ${ }^{1, b}$ \\ ${ }^{1}$ Hangzhou Dianzi University, Xiasha Higher Education Zone, Hangzhou, 310018, Zhejiang \\ Province, China \\ ashenbaohua@hdu.edu.cn, bjiangjuan@hdu.edu.cn \\ *The corresponding author
}

\section{Keywords: Express service; Low carbon model; Study on network optimization}

\begin{abstract}
Since entering twenty-first Century, with the continuous improvement of people's living standards, people's way of life has also changed greatly. Among them, online shopping is the most common way of life; it also promotes the development of China's express delivery industry. However, China's express delivery companies have just started, so it has not formed a complete system, which led to its internal chaos, pollution and other issues. And in our country to advocate energy conservation and environmental protection today, this kind of operation mode of express industry is inevitable contrary to the current low carbon economy in China's social development mode. To this end, in order to ensure the good operation of the courier companies, it is necessary to in-depth analyze the contradiction between the requirements of the low carbon economy and express the status quo, and then seek a suitable development model of the courier industry.
\end{abstract}

\section{Introduction}

In recent years, with the deterioration of the global climate, governments in the world have reached the same energy-saving emission reduction policies, that is, the development of low carbon economy. Therefore, our country responding to the world's call requires of all walks of life to take certain measures to achieve low carbon emissions, and express industry as an important support of national economy in our country which in China's current economic activity is becoming more and more important. When people enjoy the pleasure of shopping on the Internet, it will inevitably bring about a large scale of negative impact on society. It will inevitably produce a lot of garbage every day. Therefore, in order to eliminate this undesirable situation, it should start from the reality, to achieve the green, low carbon development model of express industry development. Below, this article did a detailed study of the low carbon development model on the Internet in the context of the background of the express industry.

\section{The Present Stage of China's Express Industry}

Express industry, born in the United States in the middle of the last century, and after more than half a century of development, has become one of the important social industries which provide a great convenience not only for the broad masses of people, but also for economic development and has made important contributions to offer. According to the data show, China's online shopping market is growing at a percentage of nearly $40 \%$ annually. So, at this background, express delivery industry presents the explosive growth 。 at present, more than 7000 Enterprises have obtained Express business license in china, At the same time, many large courier companies are born, such as Shen Tong, tact, in the pass, rhyme etc, whose networks are rapidly expanding from the east to the west, the city to the suburbs. Currently, we generally believe that express has the following features: The first is to provide customs clearance and logistics services for the goods transfer, and then to meet the requirements of different groups; The second is to collect quickly all kinds of the original, documents, goods, and to the whole process of these items to carry out real-time tracking 
and effective control during whole process for these items. Express industry in the operation of the process as follows: firstly,

Customers who demand to send the goods send goods to the delivery point, In this process, you can make the phone call to allow the courier to pick up the way, can also personally send their own items to the express delivery point. Then express outlets is responsible for the distribution and classification of customer's goods in different areas, and carry out a simple packaging processing, and then after classification processing, and then arrange special vehicles to transport, which should be timely to accept the dispatch of regional distribution center. Secondly, when the delivery vehicle send all express collected from express courier network to distribution center, then allocate and transport. Moreover, when the different directions express is transported to the corresponding Express outlets, each responsible for the courier will be sent to the address information to be sent to the customer's hands; so far, they completed the entire courier process.

\section{The Problem Analysis of Express Industry to Realize Low Carbon Emission}

Because of the Legal Policy Is not Perfect, Lead to the Chaos of Society. Viewing the development of our country express delivery industry, is still in the overall upward trend so more and more people have seen its potentiality, and threshold being relatively low, when the popularity of the express crashed in the community , Many entrepreneurs rush, seriously affected the normal operation of social order. Since entering twenty-first Century, in order to adapt to the development of low carbon economy, China has successively promulgated a number of national programs to deal with climate change such as "Energy conservation law", "Renewable energy law", "Circular Economy Promotion Law", "logistics industry development and adjustment plan" and so on which is our country legal policy in order to regulate the development of the express industry and the promulgation. However, due to inadequate enforcement efforts, coupled with inadequate supervision, and thus make the courier industry a lot of violations of moral social phenomenon, which has a serious impact on social security. Finally, because the government did not make a clear specification of the development of the express industry, many express enterprises in the process of development is not focusing on energy saving and environmental protection, but also seriously affect the social order, resulting in social chaos.

Express Delivery Companies Consume Higher Energy in the Transport of. Transportation is an important function of the express delivery companies in the distribution process, which is an important part of carbon emissions, therefore, the transportation process requires careful planning and adjustment, so as to meet the requirements of the country's low carbon emissions. Express delivery companies in the transport link will not only lead to higher energy consumption, but also the higher cost of transport; According to statistics, in 2014, the total cost of social logistics in China has exceeded 10 trillion yuan with the annual growth rate of $7 \%$ in the continuous growth. Compared with western developed countries, china's express delivery industry in transportation energy use rate and energy recovery rate was significantly lower, and the irrational transportation and distribution, also caused many no-load, invalid transport, transport and convective transport unreasonable phenomenon, led to the serious waste of energy. Express industry's rapid development has also brought a lot of energy consumption and pollutant emissions; Transportation is the basis for the development of express delivery, express industry in addition to providing convenience to people outside, more sophisticated being fast, so the transport industry chooses transport modes for the transport of cars and air transport, which in the transport process, the energy required for the general class is mostly oil and electricity. This type of energy will produce a large amount of pollutants, and the consumption of energy is relatively large. At present our country for the development of new energy is still in the initial stage, and has not been a large-scale promotion, so the courier industry in terms of transport needs to spend a lot of energy

Most Express Delivery Companies Are Difficult to Achieve Green in the Express Package. By 2013, china's express delivery industry has reached 9 billion 200 million of the volume of business and huge amount of business has also produced a lot of garbage. All of these parcels are 
produced by the use of packaging materials. Among them, white cardboard, envelopes, plastic bags, cartons, cushion, packing tape are the necessary packaging materials for the courier industry in the development process. Most of the courier companies based on cost considerations are given priority to some low-cost materials, although the material is not conducive to environmental protection after use. Among them, the black gray material is one of the most widely used materials and this new material bag left a lot of harmful substances, and even become a new round of "environmental killer" . In addition, the courier industry covers the storage, transportation, packaging, loading and unloading and distribution links in traditional logistics, and in the delivery, each link will have a waste generated with the increasing scale of express transport, also produced a lot of waste, many parcels used in plastic bags, foam film, etc., this are often not recycled. When the recipient received the shipment, the outer layer of the package material is often discarded, and even more some don't recycle the carton materials, resulting in a large-scale environmental pollution.

\section{Analysis on the Strategy of Constructing the Development Model of Low Carbon Express Industry in the Network Environment}

The Government Should Strengthen the Macro Policy. Low carbon express delivery business model is the future direction of the development of the community express industry, but many areas of our country are still in the initial stage, and some of the economically underdeveloped areas have not even started low carbon express industry model. To this end, the government should strengthen policy guidance, can set a number of incentives to promote low carbon development of express delivery industry; Government departments should make a series of laws and regulations according to the low carbon development goal of the national environmental protection policy, Require the courier industry practitioners to seriously implement, and then promote the courier industry's low carbon upgrade. - Secondly, in order to reduce transportation costs, the energy consumption in the transport process, the multimodal transport should be encouraged; Multimodal transport mode not only greatly improve the efficiency of delivery, solve the temporal and spatial differences in the environment, but also provide transport routes and transport mode for the majority of transport, realizing the optimization and efficient in transport process. In order to achieve a real low carbon transport, a number of courier companies should also open alliance mode, through a reasonable planning route, common distribution to reduce the pressure on the traffic process, thereby reduce the pressure on the environment. Lastly, it's to strengthen the use of clean energy. Many express companies in the course of the goods transportation by air and car transport in two ways Causing a large amount of energy consumption, so, the government should encourage courier companies to use clean energy instead of coal, oil and other nonrenewable energy sources, but also encourage the use of new clean energy delivery and handling tools to reduce pollutant emissions

Express Enterprises Should Change the Business Philosophy in a Timely manner. Firstly, the courier companies should establish a correct concept of low carbon business; in the past, people often mistakenly think that low carbon is put into higher costs, from a realistic point, the concept of low carbon business management and the idea of enterprise cost savings is the same. Therefore, enterprises should change the traditional concept of the traditional courier industry timely to ensure the effective operation of low carbon. Secondly, enterprises should also strengthen the internal information construction. Express company's service products are often based on distribution services, so in order to provide more quality services to the masses, enterprises should strengthen the construction of information, and establish a sound information service system. Only to ensure that the information system is perfect, can truly achieve the good cooperation between customers, enterprises and businesses, and thus improve the work efficiency, And the realization of enterprise information construction, further makes the use of all kinds of information technology and equipment get promotion, to enhance the level of service at the same time also accelerated the express mechanical classification operation, so as to realize the low carbon development

Express Companies Should Go for Green Packaging. Firstly, express packaging materials should choose some of the degradable materials which after abandoned can be decomposed by 
microorganisms in the soil under sunlight, at the end ,return to the ecological environment by the way of inorganic salt to promote plant absorption and growth. Secondly, express companies should use the recycle standard packaging, for different express items should chose right size to make standard packaging, according to the different needs of the capacity can be divided into large and medium small three models, and then in the choice of models to allocate which can greatly reduce the human resource, but also save the load space and save the cost. Finally, the courier industry should strengthen the recycling of cardboard boxes. Under the network environment, although online shopping has provided you with more convenience, but also has brought a large profit to the courier industry, but also has accelerated the waste of many packaging materials. Among them, the carton being one of the most consumed materials, for this purpose, the courier industry should develop some measures to recycle these recyclable carton materials, which is an important measure to achieve low carbon emissions.

The Country Should Strengthen the Propaganda Work of Low Carbon Environmental Protection to Raise The Awareness of the Whole People. The development of low carbon economy needs the joint efforts of the masses. For this, the country should strengthen the propaganda work of low carbon environmental protection and raise the awareness of the whole people's environmental protection. In the courier industry continues to develop today, although logistics transport bring more convenience to the majority of people, a lot of express in transport process requires a lot of energy, but also produce a lot of garbage, seriously affecting the city appearance. If we want to change this phenomenon, we must get the joint efforts of the whole people. Due to people's environmental awareness is low, most of the direct dumping of garbage landfill, which influenced the water, soil, air pollution. To this end, improving the people's awareness of low carbon environmental protection is very important, and local government departments must do a good job of low carbon economic development of publicity, and do a good guide and demonstration of the masses, so that the courier industry can achieve low carbon development

\section{Summary}

In summary, in the rapid development of the courier industry today, express delivery companies to achieve low carbon logistics, green transport mode of transmission is essential。 The development of low carbon mode not only can response to environmental policy of national energy conservation and emission reduction, but also promote the development of circular economy and has played an important role in promoting the establishment of resource-saving and environment-friendly society.

\section{Acknowledgements}

Supported by the Department of Education of Zhejiang Province (No.Y201533713)

\section{References}

[1] Hou Yunxian, Yang Shanqi. Study on the choice of transportation mode and the time value of passengers Taiyuan - Beijing passenger corridor as an example [J]. Journal of Beijing Jiaotong University (SOCIAL SCIENCE EDITION). 2016 (02)

[2] Cao Jiandong, Zheng Sifa, Wang Jianqiang, Lian xiao min.A fast algorithm for the simultaneous optimization of the setting delivery path [J].Journal of Tsinghua University (NATURAL SCIENCE EDITION). Preview. 2008 (08)

[3] Wang Haijun, Du Lijing, Ma Shihua. Dual objective open location in post-earthquake emergency logistics system: routing problem model and algorithm research [J]. Journal of management engineering. 2016 (02) 
[4] Song Jun, Xu Yibo, Sheng Wei, Ran Maohao. Right, design and Simulate the city logistics transit site real-time dynamic empty car distribution algorithm [J].Logistics technology. 2016 (02)

[5] Fan Xiucheng, Du Jiangang. Influence of service quality five dimensions on service satisfaction and service loyalty-- An Empirical Study on the service industry in China during the transition period: 2006 (06) (): [J]..

[6] Wang Yonggui. An analysis of the relationship between service quality, customer satisfaction and customer value -- Based on the integration framework of the telecommunications industry [J]. Journal of Wuhan University of Technology (SOCIAL SCIENCE EDITION). 2002 (06)

[7] Huang Huanzong. Evaluation of regional logistics industry competitiveness based on entropy weight method and its advantages and disadvantages-- Taking the data of the cities of Fujian Province as an example [J]. Journal of Anqing Teachers College (NATURAL SCIENCE EDITION). 2016 (01)

[8] Xie Ruhe, Li Zhifeng. Discussion and Empirical Analysis on the competitiveness index system of Chinese private express delivery enterprises [J]. Journal of Guangzhou University (SOCIAL SCIENCE EDITION). 2008 (06)

[9] Li Ming, Yan Nan nan. Research on the location of the reverse logistics network for the scrap automobile based on low carbon [J]. Journal of Chongqing Jiaotong University (NATURAL SCIENCE EDITION).

[10]Peng Shanshan, Wang Dandan, Lu Kebin, Luo Haixing. Research on distribution network layout of express delivery industry [J]. Journal of Xichang College (NATURAL SCIENCE EDITION). 2016 (01) 